\title{
Assessing Extensive Semi-Arid Rangeland Beef Cow-Calf Welfare in Namibia: Part 1: Comparison between Farm Production System's Effect on the Welfare of Beef Cows
}

\author{
Yolande Baby Kaurivi ${ }^{1} * \mathbb{C}^{\mathbb{D}}$, Richard Laven ${ }^{1} \mathbb{D}$, Tim Parkinson ${ }^{1}$, Rebecca Hickson ${ }^{2} \mathbb{D}$ and Kevin Stafford ${ }^{2}$ \\ 1 School of Veterinary Medicine, Massey University, Private Bag 11 222, Palmerston North 4442, New Zealand; \\ r.laven@massey.ac.nz (R.L.); t.j.parkinson@massey.ac.nz (T.P.) \\ 2 School of Agriculture and Environmental Management, Massey University, Private Bag 11 222, \\ Palmerston North 4442, New Zealand; R.Hickson@massey.ac.nz (R.H.); k.j.stafford@massey.ac.nz (K.S.) \\ * Correspondence: Y.Kaurivi@massey.ac.nz; Tel.: +64-63505328
}

check for

updates

Citation: Kaurivi, Y.B.; Laven, R.; Parkinson, T.; Hickson, R.; Stafford, K. Assessing Extensive Semi-Arid Rangeland Beef Cow-Calf Welfare in Namibia: Part 1: Comparison between Farm Production System's Effect on the Welfare of Beef Cows. Animals 2021, 11, 165. https:// doi.org/10.3390/ani11010165

Received: 3 December 2020 Accepted: 10 January 2021 Published: 12 January 2021

Publisher's Note: MDPI stays neutral with regard to jurisdictional clai$\mathrm{ms}$ in published maps and institutional affiliations.

Copyright: (C) 2021 by the authors. Licensee MDPI, Basel, Switzerland. This article is an open access article distributed under the terms and conditions of the Creative Commons Attribution (CC BY) license (https:// creativecommons.org/licenses/by/ $4.0 /)$.
Simple Summary: Namibia is in the process of updating animal welfare legislation. This needs to include an assessment protocol for beef cattle production systems that is sufficiently rigorous for the country to gain and maintain access to high-value beef export markets. Beef is produced in commercial and semi-commercial systems and in communal village farms. Privately owned commercial farms allow maximum herd and rangeland management to ensure optimum productivity and profitability. Village farms (semi-commercial and communal) have limited grazing land, with consequent challenges of grazing and water management, as well as traditional customs of cattle management. A protocol was developed to assess the welfare of beef cattle in the context of these production systems. The application of the welfare assessment protocol indicated that the standards of welfare differed across production systems, with commercial farms achieving the best standard of welfare, followed by semi-commercial, then communal village farms. The greatest opportunity for change exists within the semi-commercial village farms, which need to attain to the requirements imposed by international markets to maximize their returns; hence herd management and welfare status is better than in the purely communal farms. This suggests that commercialization of communal farming may have benefits for animal welfare.

Abstract: A proposed animal welfare assessment protocol for semi-arid rangeland-based cowcalf systems in Namibia combined 40 measures from a protocol developed for beef cattle in New Zealand with additional Namibia-specific measures. Preliminary validation of the protocol had been undertaken with five herds in one semi-commercial village. The aim of the current study was to apply this protocol and compare animal welfare across three cow-calf production systems in Namibia. A total of 2529 beef cows were evaluated during pregnancy testing in the yards of 17 commercial, 20 semi-commercial, and 18 communal (total: 55) herds followed by an assessment of farm resources and a questionnaire-guided interview. Non-parametric tests were used to evaluate the difference in the welfare scores between the production systems. The results indicated a discrepancy of animal welfare between the three farm types, with a marked separation of commercial farms from semi-commercial, and communal village farms in the least. The differences in these production systems were mainly driven by economic gains through access to better beef export market for commercial farms and semi-commercial villages, as well as by the differences in the available grazing land, facility designs/quality, and traditional customs in the village systems. The results indicate an advantage of commercialization over communalization.

Keywords: animal welfare assessment; beef cow systems; semi-arid rangelands; Namibia 


\section{Introduction}

Namibian beef farming is dependent on extensive grazing under semi-arid, rain-fed conditions [1,2]. The beef cattle industry is predominantly driven by the demarcation of Namibia into two parts (northern and southern) by the veterinary cordon fence (VCF; see Figure 1). The VCF is an important biosecurity measure for animal disease control, particularly for contagious bovine pleuropneumonia and foot and mouth disease (FMD). North of the VCF, livestock and livestock products are not eligible for overseas export because of the risk of FMD which is endemic in north-east Namibia [3,4]. All farming rangeland north of the VCF is allocated to communal farmers with customary tenure $[5,6]$. Most households in these areas are subsistence-based and labor intensive, with inadequate access to technology [6].

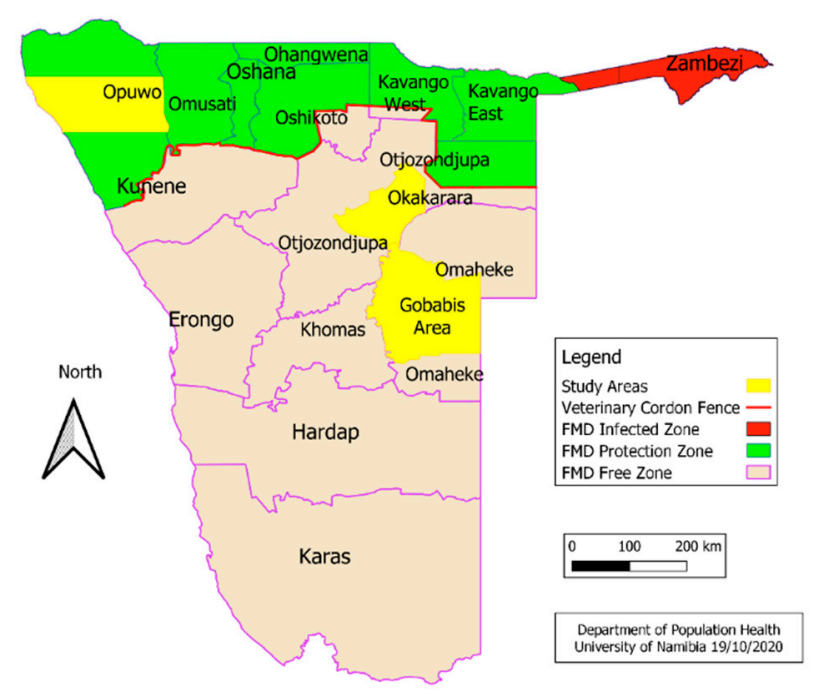

Figure 1. Namibia regional map showing the foot and mouth disease (FMD) zones and fences and study areas for commercial (Gobabis area), semi-commercial (Okakarara area) and communal farming (Opuwo area) [4], (source Dr Alec Bishi).

The southern part of Namibia (below the VCF) was declared FMD free by the World Organisation for Animal Health (OIE) and can export beef to overseas markets [4]. In this zone there are two types of farms; privately owned commercial farms [2] and communally owned village farms with customary tenure. The latter "semi-commercial" village farms are set-up in the same way as communal village farms north of the VCF but have access to high-value commercial and overseas markets [6,7]. The line of these two systems is also blurred by the resettlement freehold farms where the Namibian government buys farms from commercial farmers and resettle people mostly from communal areas.

These three different beef farming systems, commercial, semi-commercial and communal, have different management styles, income streams, and levels of productivity. Commercial farms are farms that are not communally owned, have livestock grazing behind fences, and where the focus of beef farming is principally commercial rather than being a traditional tribal practice. In contrast, both semi-commercial and communal villagers farm in communal areas. The main difference between the two is that semi-commercial farms have access to commercial markets and thus have different cattle marketing and management strategies, but in both systems, traditional tribal practices in relation to cattle farming are important. In this paper we use the term village farms as an inclusive term for both semi-commercial and communal farms, as a way of contrasting these communal farms to commercial beef farms.

These differences are likely to have a significant effect on cattle welfare, although there are no data on beef cattle welfare on Namibian beef farms. In part, this dearth of information is because there is no standardized system of independent assessment of 
animal welfare under Namibian production systems. However, welfare assessment is commonly demanded by the type of markets to which Namibian farm animal products are exported. Importing countries commonly have welfare assessments that are applied to their domestic beef production, but such assessments are focused upon the species and production systems that pertain in those countries [8-10], and do not take into consideration the conditions that pertain in (for example) the semi-arid conditions of countries such as Namibia. Thus, as different systems need different welfare assessment protocols [11,12], the value of developing a system of welfare assessment that was relevant to Namibian conditions became evident.

As part of a project to create welfare assessment protocols for extensively reared beef cattle in the semi-arid conditions of Namibia, Kaurivi [13] assessed the use of a protocol that was originally developed for New Zealand semi-intensive temperate pastoral beef production systems (based on the Welfare Quality protocol [14] and University of California Davis protocol [15]). The protocol was validated on five herds in one semicommercial village in Namibia. That preliminary study identified nine further Namibianspecific measures that could be incorporated into the protocol to make it suitable for use on Namibian beef farms. By using the protocol on commercial, semi-commercial, and communal beef farms in Namibia, the aim of this study, was to confirm that conclusion and to determine the impact of farm system on the welfare of Namibian beef cows.

\section{Materials and Methods}

Three areas were selected for inclusion in the study based on being representative of their farm type within Namibia. The herds included in the study were a convenience selection based on the willingness of the farmers to be involved. A total of 55 herds were enrolled, 17 commercial herds (from 17 separate farms), 20 semi-commercial herds (from 8 villages) and 18 communal herds (from 8 villages). Thus, both semi-commercial and communal farms were village-based, with multiple herds examined per village. Details of these herds are given in Table 1.

Table 1. Study areas for commercial, semi-commercial, and communal farming areas showing number of herds, farms/villages and number of cows assessed.

\begin{tabular}{|c|c|c|c|c|c|c|c|c|c|c|}
\hline \multirow{2}{*}{$\begin{array}{l}\text { Beef Cattle } \\
\text { System }\end{array}$} & \multirow{2}{*}{ Area } & \multirow{2}{*}{$\begin{array}{l}\text { No. of Herds } \\
\text { Assessed }\end{array}$} & \multirow{2}{*}{$\begin{array}{c}\text { No. of } \\
\text { Farms/Villages }\end{array}$} & \multirow{2}{*}{$\begin{array}{l}\text { Total } \\
\text { Cattle }\end{array}$} & \multirow{2}{*}{$\begin{array}{c}\text { Average } \\
\text { Cattle/Herd }\end{array}$} & \multirow{2}{*}{$\begin{array}{c}\text { Total } \\
\text { Cow/Heifers }\end{array}$} & \multicolumn{4}{|c|}{ No of Cows/Heifers Assessed } \\
\hline & & & & & & & Average & Min & Max & Total \\
\hline Commercial & Gobabis & 17 & 17 & 5887 & 346 & 3923 & 76.7 & 34 & 141 & 1305 \\
\hline Semi-commercial & Okakarara & 20 & 8 & 2196 & 110 & 1590 & 29.7 & 11 & 55 & 593 \\
\hline Communal & Opuwo & 18 & 8 & 4563 & 254 & 2485 & 35.1 & 8 & 78 & 631 \\
\hline
\end{tabular}

Both semi-commercial and communal villagers farm in communal areas (village farms). The main difference between the two is that semi-commercial farms have access to commercial markets and thus have different cattle marketing and management strategies. In this paper, we use the term "village farms" as an inclusive term to include both semi-commercial and communal farms, to contrast them with commercial farms which are not communally owned, which have livestock grazing behind fences, and where the focus of beef farming is principally commercial rather than being a traditional tribal practice.

\subsection{Description of the Study Areas}

Commercial farming system: (Gobabis area, Omaheke region, eastern Namibia, lat $22^{\circ} 26^{\prime} \mathrm{S}$, long $18^{\circ} 58^{\prime} \mathrm{E}$ ). Commercial farms are large farms (range 3000-10,000 ha) that have a boundary fence and fenced grazing paddocks [16]. On most farms (every farm represents one herd), the owners are full-time farmers or employ managers [2]. On the study farms, beef cattle farming was the predominant economic activity of interest, through auctioning or direct abattoir marketing of cattle. Cattle farming was supplemented by small stock (sheep and goats) farming and wildlife ranching. Horses were commonly used for cattle mustering on most farms. The principal beef breed was Brahman, alongside pure breeds or crosses of Simmental, Charolaise, Bonsmara, Afrikaner, and Nguni. The area is a flat sandy thorn-bush highland with predominant open acacia savannah-type vegetation [17]. Annual rainfall in the area ranged between $200-400 \mathrm{~mm}(\sim 2 / 3$ in January-March) and average annual temperature is $19.3^{\circ} \mathrm{C}$; ranging from $0{ }^{\circ} \mathrm{C}$ in winter to $33^{\circ} \mathrm{C}$ in summer [18]. 
Semi-commercial farming system: (Okakarara area, Otjozondjupa region, central Namibia, lat $20^{\circ} 35^{\prime} \mathrm{S}$, long $17^{\circ} 27^{\prime} \mathrm{E}$ ). In a semi-commercial village farm, multiple families use the same permanent communal land for grazing and water. The land is governmentowned with limited or no internal and external border fencing and animals roam freely $[5,19]$. Semi-commercial village farmers in Okakarara are mainly dependent on livestock production (multi-purpose cattle, sheep and goats) for their livelihood. Weaner calf trading at auctions was the main marketing activity. In the study area, the grazing area associated with an individual village ranged from $\sim 3000$ to 6000 ha, with $~ 10-30$ families/households per village. Herds were selected for inclusion on a convenience basis with $1-5$ herds selected from each of eight separate villages (total $n=20$ herds; Table 1 ). In one of the eight study villages, government-built, village-maintained, common cattle handling facilities (yard with a race) were available; in the other villages, farmers were responsible for erecting their own facilities. Some households, without adequate handling facilities, took their cattle to yards with better facilities on days of mass handling. The principal beef breed was Brahman, alongside crosses with Simmental, Hereford, Nguni, and Sanga. The area is a sandy thorn-bush highland acacia savannah [7]. Annual rainfall in the area ranged between $100-430 \mathrm{~mm}(\sim 2 / 3$ in January-March) and average annual temperature was $19.6^{\circ} \mathrm{C}$; ranging from $0{ }^{\circ} \mathrm{C}$ in winter to $32^{\circ} \mathrm{C}$ in summer [18].

Communal farming system: (Opuwo/Kaokoland area, Kunene region, north-western Namibia, lat $18^{\circ} 3^{\prime} \mathrm{S}$, long $13^{\circ} 51^{\prime} \mathrm{E}$ ). As in semi-commercial villages, in communal villages, animals of different households graze together on the same government-owned communal land with limited or no internal and external border fencing. The small cattle herds were mainly kept for subsistence purposes and were mostly multi-purpose; i.e., milk and meat as well as manure for fire and building houses. Cattle farming was supplemented by herds of goats and some sheep. In the study area, farmers tend to be semi-nomadic with livestock being moved from permanent structures (yards and water troughs) to temporary ones in seasons of limited grazing (e.g., winter or drought). Cattle marketing was mainly for oxen (more than 2 years old bullocks) and cattle must go through a quarantining system, before slaughter at an approved abattoir a long distance away. In this area, the government had constructed community crush pens (forcing pen and race only) within $\sim 3 \mathrm{~km}$ of each village. These were completed and maintained by the villagers. The main breed in the area was indigenous Sanga cattle alongside Nguni and Brahman crosses. Average cattle herd size was 254 cattle, ranging from 30-548 cattle (one herd with 1900 cattle was owned by multiple members of the same family but managed as one group). From the selected eight villages, a selection of 2-5 herds per village farm was included in the study (total $n=18$ herds; Table 1). The area vegetation is classified as mopane savannah with shrublandwoodland mosaic vegetation partly with rocky and bare mountains [20]. Annual rainfall in the area ranged between 50-320 mm ( 2/3 in January-March) and average annual temperature was $21.6{ }^{\circ} \mathrm{C}$; ranging from $10{ }^{\circ} \mathrm{C}$ in winter to $30^{\circ} \mathrm{C}$ in summer [18].

\subsection{Welfare Assessment and Data Collection}

The welfare assessments took place in March/April 2019 (autumn). The protocol was used on 55 herds with animal-based measures being assessed on 2529 cows (Table 1). (See Appendix A for protocol and description of measures). All animal-based and handling assessments were made during pregnancy testing, with all cows presented for pregnancy testing being assessed on each herd. On farms where a race was present, pregnancy testing was undertaken in the race. In the absence of a race, cows were captured with ropes (as if for milking) and pregnancy tested while standing (or lying) in a holding pen.

All observations were made by the same observer (first author). For each herd, the observer took a general overview of the cows in holding pens, before observations of body condition, rumen fill, behavior, and physical health were made in single-file races (or in pens where there were no races). Stockpersonship was evaluated as cows entered, were handled and exited the race or the pens. Information was collected on yard design and accessibility (i.e., shape and size of forcing pens, race structure as well as cow flow 
and effective handling from pens to race). As animals exited the race (or pens), their exit speed (running or walking), whether they fell or stumbled, and lameness signs were all recorded. Depending on accessibility and race design, the position of the assessor varied from standing on the side of the race or in pens as cattle moved around. For observation of cows exiting the race/pens the observer stood as close to the exit as possible without interfering with cow flow.

A farm resource visit and a questionnaire-guided interview were conducted to assess health and management of each herd over the last 12 months. These included records of dehorning/disbudding, castration, vaccination, diseases, or disease symptoms seen in cattle, cattle deaths, access to water and grazing and wintering practices. (See Appendix B for questionnaire).

\subsection{Data Analysis}

All data were analyzed using IBM SPSS Statistics for Windows Version 24 (IBM Corp. Released 2016. Armonk, New York, USA). Descriptive statistics for continuous measures were used to capture central tendency (median), and range (minimum and maximum). The effect of farm type on continuous measures of welfare was analyzed by using the KruskalWallis test, and on categorical measures using the Fisher's exact test. Where the $p$-value was $<0.2$ for either test, post-hoc testing was used for pairwise comparisons (Dunn test for continuous measures, and Fisher's exact for categorical). Holm-Bonferroni correction was used to account for multiple comparisons. For this analysis $\alpha$ was set at 0.05 .

\section{Results}

The proposed protocol took on average $2.5 \mathrm{~h}$ for a 100 -cow herd at commercial farms (yard assessment- 1 hour and questionnaire and farm resource visit-1.5 h) and $2.5 \mathrm{~h}$ for a 50-cow herd at the village farms (semi-commercial + communal).

\subsection{Continuous Measures}

The median and range for the 30 continuous indicators included in the assessment are shown in Table 2 (mean ranks for these measures are shown in Appendix C). Of those measures, only one, broken tails, had no recording on any farm of any type. Five measures (dirtiness, blindness, ocular and nasal discharge and poisoning deaths) had medians of 0 on all three farm types. Of the other 24 measures, commercial herds had the lowest median for 15 (including one tie) and the highest median for seven (including one tie). Semi-commercial herds had the lowest median for 9 (including three ties) and highest median for two. In contrast communal herds had the lowest median for three measures (including two ties) and highest median for 16 measures (including one tie).

No effect of farm type was identified on the numbers of cattle affected with 14/24 measures (swelling, blindness, ocular and nasal discharges, dystocia, fly burden, deaths from disease, accident, culling or poisoning, fearful behavior, falling/lying, stumbling or run$\operatorname{ning}(p \geq 0.35))$. Of the measures where the Kruskal-Wallis test returned a $p$-value of 0.05 to 0.2 (i.e., blindness, fly burden, run and excess branding/wounds), none could be separated by farm category using the Dunn test. As such, the lowest adjusted $p$-value for a pairwise comparison was $>0.0167$ in all cases, as there were 3 pairwise comparisons (commercial vs. semi-commercial and communal and semi-commercial vs. communal), and using the Holm-Bonferroni correction all pairwise comparisons are statistically non-significant if the lowest $p$-value is $>0.05 / 3$.

For the remaining measures, grouping by farm category using the Dunn test is shown in Table 3. The analysis separated the three farm types for proportion of emaciated cows and proportion of cows with poor rumen fill. In both cases, the median was lowest on commercial herds $(0 \%)$ and highest in communal herds $(83.9 \%$ and $78.9 \%)$, with semicommercial herds (13\% and 48.1\%) in between the two. For long/sharp horns, hair loss, tick burden and mortality, commercial herds were separated by the analysis from semi- 
commercial and communal herds, but the analysis did not separate the village farms. In all cases, the median was lowest on commercial herds (see Table 2).

Table 2. Descriptive analysis (median and range in percentage) of continuous welfare indicators in three Namibian beef production systems.

\begin{tabular}{|c|c|c|c|}
\hline Measure & Commercial $(n=17)$ & Semi-Commercial $(n=20)$ & Communal $(n=18)$ \\
\hline Thin cows & $2.5(0-46.9)$ & $78.3(25-100)$ & $100(83.3-100)$ \\
\hline Emaciated cows & 0 & $7.3(0-40)$ & $83.9(52.5-100)$ \\
\hline Poor rumen fill & $0(0-45.2)$ & $48.1(14.3-100)$ & $78.9(39.3-100)$ \\
\hline Dirtiness & $0(0-8.8)$ & 0 & $0(0-16.7)$ \\
\hline Swelling & $1.7(0-8.2)$ & $3.7(0-37.1)$ & $2.3(0-13.3)$ \\
\hline Hair loss & $0(0-2.8)$ & $2.8(0-16.7)$ & $5.3(0-20)$ \\
\hline Abrasion & $2.8(0-12.5)$ & $5.6(0-27.3)$ & $19(1.8-40)$ \\
\hline $\begin{array}{c}\text { Multiple } \\
\text { brands/wounds/cuts }\end{array}$ & $0.8(0-3.6)$ & $2.8(0-44.4)$ & $5.3(0-87.5)$ \\
\hline Broken tail & 0 & 0 & 0 \\
\hline Long/sharp horns & $2.5(0-37)$ & $40.5(10-96.6)$ & $61.8(13.1-85)$ \\
\hline Blindness & $0(0-2.5)$ & 0 & $0(0-1.3)$ \\
\hline Ocular discharge & $0(0-1.4)$ & 0 & $0(0-1.3)$ \\
\hline Nasal discharge & $0(0-1.4)$ & 0 & $0(0-1.3)$ \\
\hline Diarrhea & $0.9(0-12.9)$ & $0(0-1.8)$ & $4.3(0-25)$ \\
\hline Lameness & $0(0-3.9)$ & $0(0-3.3)$ & $3.4(0-16.7)$ \\
\hline Dystocia & $0.8(0-3.3)$ & $1(0-10.0)$ & $1.4(0-6.7)$ \\
\hline Tick burden & $0(0-6.8)$ & $1.4(0-81.3)$ & $4.4(0-35)$ \\
\hline Fly burden & $0(0-12.3)$ & $1.4(0-61.5)$ & $4.5(0-55)$ \\
\hline Deaths from diseases & $0.7(0-4.1)$ & $0(0-2)$ & $0.4(0-7.9)$ \\
\hline Accidental deaths & $0.2(0-1.6)$ & $0(0-3)$ & $0.1(0-16)$ \\
\hline Culling for health & $0.2(0-2.3)$ & $0(0-3.1)$ & $0(0-3.3)$ \\
\hline Predation/snake bite deaths & $0.4(0-9)$ & $0(0-4.1)$ & $4(0-20)$ \\
\hline${ }^{*}$ Nutritional deaths & $0(0-3.2)$ & $6.6(0-50)$ & $1.1(0-10)$ \\
\hline *Poisoning deaths & 0 & $0(0-2.4)$ & $0(0-0.3)$ \\
\hline *Reproduction deaths & $0.2(0-0.8)$ & $0(0-4)$ & $0.2(0-2.6)$ \\
\hline Annual mortality rate & $2.4(0-15.5)$ & $11.3(0-26.9)$ & $11.7(2.2-26)$ \\
\hline Fearful/Agitate & $3(0-25)$ & $6.2(0-19.4)$ & $7.7(0-17.5)$ \\
\hline Fall/lie & $5.8(0-17.7)$ & $3.4(0-26.7)$ & $5(0-17.5)$ \\
\hline Stumble & $1.4(0-4.9)$ & $0(0-40)$ & $0(0-14.3)$ \\
\hline Run exit & $3.8(0-16.9)$ & $1(0-20)$ & $0.8(0-15)$ \\
\hline
\end{tabular}

Highest median(s) for each category is in bold (if $>0$ ). See Appendix A for description of how each measure was assessed. ${ }^{*}$ Nutritional deaths included weight loss and mineral deficiency (e.g., phosphate) deaths. *Poisoning deaths were plant poisonings and other poisonings (e.g., urea). *Reproduction related deaths included dystocia, retained placenta, and vaginal prolapse complications.

Table 3. Groupings by farm category (1: Commercial $(n=17)$, 2: Semi-commercial $(n=20)$, 3: Communal $(n=18))$, using the Dunn test (with Holm-Bonferroni correction for multiple comparisons)).

\begin{tabular}{cc}
\hline Farm Grouping & Measures \\
\hline $1<2<3$ & Emaciated, poor rumen fill \\
$1<2,1<3,2=3$ & Thin, horns, hair loss, ticks, mortality rate \\
$2<3,1=2,1=3$ & Dirtiness \\
$1<3,2<3,1=2$ & Abrasion, lameness, predator deaths \\
$2<3,2<1,1=3$ & Diarrhea, reproduction deaths \\
$1<2,3<2,1=3$ & Deficiency (nutritional) deaths \\
\hline
\end{tabular}

The analysis for dirtiness showed no separation between commercial and semicommercial herds or between commercial and communal herds but separated semicommercial from communal herds. Although in all farm types, the median was 0 , semicommercial herds had a lower mean rank than communal herds. The comparison of farm effects for diarrhea and reproduction deaths separated semi-commercial from commercial 
and communal herds but did not separate commercial from communal herds. In both cases, semi-commercial had the lowest median value and communal had the highest (Table 2).

There was an effect of farm type on the proportion of cows with skin abrasion and lameness, and the number of reported predator deaths. The analysis separated commercial and semi-commercial herds from communal herds, but not commercial from semicommercial herds. In both these cases the median was highest in communal herds (Table 2). For deaths associated with nutritional deficiency, the analysis separated semi-commercial herds (which had the highest median) from commercial and communal herds but did not separate communal and commercial herds.

\subsection{Categorical Measures}

Shade (natural savannah-type rangeland trees) was sufficient on all the farm types. The remaining frequencies of ordinal measures by farm type in each welfare category are shown in Appendix D. Commercial herds had the highest frequency of farms in the poor welfare category for 4/17 measures (dog noise, equipment noise, mis-catch, and use of electric prodders). Semi-commercial village herds had the highest frequency of farms in the poor welfare category for 4/17 measures (late castration and dehorning, hazards, and poor flow of cattle during handling). Communal herds had the highest frequency of farms in the poor welfare category for 8/17 measures (distance to water/grazing, ear tagging, hitting and tail twisting in the yards, handler noise, and yarding frequency).

Of the categorical measures, no effect of farm type was found on 4/17 measures (hazards, hitting, equipment noise, and health checks; $p>0.2$ in the initial analysis). The $p$-values for the multiple comparisons and direction of the difference for the remaining measures are shown in Table 4 . Although the overall $p$-value was $<0.2$ for mis-catch and dog noise, the analysis did not separate these measures by farm (lowest adjusted $p$-value $>0.0167$ ).

Table 4. Pairwise comparisons for the Fishers exact test for the frequency of categorical measures at the cow-calf production systems herds in Namibia ( 1 -Commercial $(n=17), 2$-Semi-commercial $(n=20)$, 3-Communal $(n=18))$.

\begin{tabular}{ccccc}
\hline Ordinal Measures & \multicolumn{3}{c}{ Fishers Exact $p$-Value } & Pairwise \\
\cline { 2 - 5 } & $\mathbf{1}$ vs. $\mathbf{2}$ & $\mathbf{1}$ vs. 3 & $\mathbf{2 ~ v s . ~ 3}$ & Outcomes \\
\hline Water distance & $<0.001$ & $<0.001$ & 1 & $1<2,1<3,2=3$ \\
\hline Grazing distance & $<0.001$ & $<0.001$ & 1 & $1<2,1<3,2=3$ \\
\hline Dehorning & 0.001 & $<0.001$ & 0.468 & $1<2,1<3,2=3$ \\
\hline Castration & 0.005 & $<0.001$ & 0.135 & $1<2,1<3,2=3$ \\
\hline Ear tagging & $<0.001$ & $<0.001$ & 0.526 & $1<2,1<3,2=3$ \\
\hline Hot-iron branding & $<0.001$ & 0.466 & $<0.001$ & $1<2,1=3,3<2$ \\
\hline Mis-catch & 0.094 & 0.019 & 0.526 & $1=2=3$ \\
\hline Electrical prodders & 0.019 & 0.015 & 1 & $2<1,3<1,2=3$ \\
\hline Tail twisting & 0.013 & 0.005 & 0.639 & $1<2,1<3,2=3$ \\
\hline Handlers noise & 0.068 & 0.005 & 0.028 & $1=2,1<3,2=3$ \\
\hline Dog noise & 0.270 & 0.019 & 0.027 & $1=2=3$ \\
\hline Yarding/handling freq. & 0.363 & $<0.001$ & $<0.001$ & $1=2,1<3,2<3$ \\
\hline Yard/handling flow & $<0.001$ & $<0.001$ & 0.512 & $1<2,1<3,2=3$ \\
\hline
\end{tabular}

Electrical prodders were only used on commercial farms, so the analysis separated commercial herds from communal and semi-commercial herds, but not communal from semi-commercial. For distance to water/grazing, dehorning, castration, ear tagging, tail twisting and yard/handling flow, the analysis separated commercial from semi-commercial 
and communal herds, but not semi-commercial from communal herds. For all these measures, commercial herds had the lowest frequency of herds with poor welfare and communal the highest frequency.

For hot-iron branding, semi-commercial herds had the highest frequency of poor welfare. The analysis separated them from commercial and communal herds but did not separate communal from commercial herds. For noise of handlers, the analysis separated commercial and communal herds (with the latter having a higher proportion of farms with poor welfare than the former) but did not separate semi-commercial herds from communal or commercial herds. For yarding/handling frequency the analysis separated communal from commercial and semi-commercial herds, but not commercial from semi-commercial herds. For this measure communal herds had the highest of herds with poor welfare

Painful management procedures: Castration was performed on $9 / 17$ commercial herds (mode and median 2 months of age; range 1 week to 8 months), 8/20 semi-commercial herds (mode and mean 6 months) and on all 18 communal herds (all after 6 months). Disbudding was performed at all commercial herds (mode 2 months; 1 week to 8 months), $17 / 20$ semi-commercial and 12/18 communal herds (mode 6 months at the villages; range 4 months to 12 months). Ear tagging was performed on all herds with median and mode of 2 months at the commercial herds and mode and median of 6 months in both types of village herds. Ear notching (cutting with a knife) was routinely performed on all village herds as a form of identification but not on the commercial herds. Skin cutting (dew-lap cuts) was performed on $7 / 20$ and $4 / 18$ herds in the semi-commercial and communal herds, respectively. Cattle branding with hot iron was used on all herds; secondary branding (i.e., letters, marks) was routinely performed on commercial stud farms (5/17 commercial farms) and on all the village herds. No anesthesia was used for any procedure.

\section{Discussion}

The current study confirmed the findings of Kaurivi [13] that a 40 measure protocol developed for use on extensive cow-calf farms in New Zealand was, with the addition of nine Namibian-specific measures, feasible for use during yarding on all classes of Namibian beef farms. The use of this protocol has identified marked differences between production systems in animal welfare. For 25 of the total 47 indicators (30 continuous +17 categorical) included in the protocol, the analysis separated welfare outcome by system. For 16/25 measures, the welfare outcome was better on commercial herds than semi-commercial herds, and for 19/25 it was better on commercial herds than communal herds (Tables 3 and 4). For 9/25 measures, semi-commercial herds had a better welfare outcome than communal herds, while communal herds had better outcomes overall than semi-commercial herds for only two measures.

The most obvious difference between farm systems was related to feeding. For proportion of emaciated cattle and proportion with poor rumen fill, commercial farms performed better than the village farms, and semi-commercial farms performed better than communal farms. This is likely to be because commercial farms have more control over cattle feed supply than village farms. Village systems also have limited fencing, which limits the ability of farmers to manage grazing $[1,19,21]$. Moreover, social obligations and customary factors contribute to a widespread failure of village farmers to undertake timely reductions of stock numbers, even when feed is scarce [7]. Nevertheless, despite these challenges, semi-commercial farmers were able to maintain cattle in better body condition score (BCS) than their communal counterparts. This may be due to the better feeding, herd management, and genetics associated with the cash income from beef sales. On the other hand, it may reflect differences between the selected regions rather than farm system. Siegmund-Schultze [7] reported that the average BCS was higher on communal than semi-commercial village farms (3.0 vs. 2.5 respectively; $1-5$ scale), concluding that this was related to feed supply, as the communal farms in northeast Namibia had significantly more rainfall than the semi-commercial farms in central Namibia (550 vs. 350 mm/year, respectively). Similar considerations may pertain to the present study, the communal farms 
were in northwest Namibia (Opuwo area), which has a much drier environment than the region (Kavango West) studied by Siegmund-Schultze [7]. Indeed, in the rainy season prior to the start of the study (i.e., September 2018-March 2019), Okakarara semi-commercial area had $>140 \mathrm{~mm}$ more rain than Opuwo (457 vs. $314 \mathrm{~mm}$, respectively). Thus, the differences of BCS in the present study may, at least partly, reflect the effect of rainfall on feed availability rather than system differences.

The distances that animals had to walk to grazing may also have exacerbated pressures upon BCS [22]. Distances are characteristically shorter on commercial farms $(2-4 \mathrm{~km})$ than on semi-commercial $(3-6 \mathrm{~km})$ or communal farms $(4-8 \mathrm{~km})$. The distance to grazing also had an impact on distance to water. In village farms, water is provided in or around the yards, so distance to water is strongly related to distance to grazing, whereas in commercial farms, water troughs are in the grazing paddocks. The relationship between BCS and lameness may therefore be of interest, since lameness was rare on commercial and semi-commercial herds (median $0 \%$ on both max. $3.9 \%$ and $3.3 \%$, respectively), but more common on communal herds (median 3.3, max 17\%). The association between the prevalence of lameness and distance walked is well recognized $[23,24]$ and cattle on communal village farms walked the longest distances. Lameness rates could be also related to handling facilities, which could cause injury and acute lameness. However, there was no difference between semi-commercial and communal herds in yard handling/flow (Table 4), despite a difference in the prevalence of lameness prevalence. The older age of cattle at communal farms could also have contributed to lameness. Finally, BCS itself can affect the risk of lameness, as poorer BCS has been associated with increased risk of lameness [25], hence, the increased lameness in communal herds could have been related to underfeeding. There is clearly a need for further research to unravel these relationships.

Differences between systems were also noted in relation to animal health. Skin abrasions/injuries were more common in communal than semi-commercial and commercial herds, probably because the quality of handling facilities on communal farms were poorer (i.e., greater use of thorny bushes and tree poles tight with wires), and thus the risk of accidental injury higher. Hairless patches were less common in commercial than semicommercial/communal farms, although this may reflect the prevalence of lumpy skin disease than of welfare per se. Relatively few animals were assessed as having diarrhea, although the prevalence was highest in communal than other herds $(4.3 \% \mathrm{vs} .0 \%$ and $0.9 \%$ at semi-commercial and commercial respectively).

There was a large difference between the median of mortality rates on commercial $(2.4 \%)$ versus semi-commercial $(11.3 \%)$ and communal $(11.7 \%)$ herds. It was likely that underlying differences between systems were exacerbated by the impact of the prevailing drought. Deaths due to predation, dystocia (reproduction) and nutrition varied between farm systems. Interestingly, death due to predation was higher in communal herds but there was no difference between commercial and semi-commercial herds. This may reflect the value of internal fencing and the ability of commercial farmers to control where cattle go (such as calving in calving camps in areas not frequented by cheetahs; [26]). Risk of death due to predation may also reflect changes in the population of wild prey associated with drought conditions $[27,28]$. Opuwo communal area borders the Etosha National Park where livestock are at a risk from predators. Deaths due to dystocia (reproduction deaths) were lowest in semi-commercial herds, but there was no difference between commercial and communal herds. However, the risk of deaths due to dystocia was not significantly related to the reported incidence of dystocia per se. There is no clear explanation for this, except to note that the rate of dystocia and reproduction deaths in communal herds was probably related to the lower plane of BCS [29]. It is likely that the higher rate of reproduction deaths on commercial farms was due to better recording of the cause of death as on commercial farms pregnant cows were kept in paddocks close to the main yards to allow for close monitoring and assistance in case of cows with difficult births.

Deaths reported as nutritional were far higher in semi-commercial than communal or commercial herds. Again, the reasons for this pattern are not clear, although the lower 
prevalence in commercial herds is consistent with better body condition and the use of supplementary feeding. Conversely, the lower prevalence on communal herds is not consistent with the higher proportion of emaciated cattle in those herds. It may be that the discrepancy lies in the effects of phosphate deficiency [30], which is widespread, but whose distribution and severity varies between the different areas included in the present study. For example, sandy soil around Okakarara areas has significantly lower phosphate than that at the harder and drier sand around Opuwo area $(3.35 \mathrm{mg} \mathrm{P} / \mathrm{kg}$; [17], vs. $12.4 \pm 1.7 \mathrm{mg} \mathrm{P} / \mathrm{kg}$; [20]), while the available soil phosphorus threshold is intermediate ( $\leq 10 \mathrm{mg} \mathrm{kg}-1 \mathrm{DM}$; [30]). A comprehensive investigation in the suspected phosphate deficiency related deaths of cattle is warranted and would help to unravel this question.

No effect of farm system on fly burden was found, but tick burdens were lowest on commercial farms. It is likely that this reflects parasite management with commercial farms using external parasite control as a key part of herd health management, whereas semi-commercial farmers treat cattle for ticks when necessary to do so (i.e., when preparing them for sale, when there are high tick burdens or in response to tick-borne diseases). No difference was found between semi-commercial and communal herds in tick burden, despite communal farmers rarely, if ever, using tick control. These data suggest that the limited use of tick control in semi-commercial herds is not having any impact on ticks.

There are issues with painful management procedures on all farm types. No anesthesia was used for any procedure on any farm. On commercial farms, dehorning/castration is generally performed when calves are younger than on village farm types (mode 2 vs. 6 months respectively). The FAN (Farm Assured Namibian) Meat scheme [31] requires that these operations are performed on calves younger than 2 months of age to ensure reduced pain and faster healing [32]. However, the FAN Meat is a voluntary scheme, and farmers in the villages have a traditional but erroneous conviction that late castration allows faster growth and muscle gain [33].

Keeping of horned cattle is traditional in the villages, but there is clear evidence of long horns injuring other animals and hampering handling flow in the race. There is increasingly strong advocacy for keeping polled cattle (which would also eliminate the need for dehorning: [34]). However, horns are natural defense tools against predators' attacks [35] and imposing such restrictions in areas that lose livestock to predators may hinder the sustainability of farming.

Hot-iron branding and ear tagging are compulsory for cattle identification and traceability in Namibia. Analgesia was not provided on any farm for cattle during or after hot-iron branding, so hot iron branding was a significant welfare concern on all farms. However, on many farms additional painful methods were used to permanently identify cattle in addition to the statutory brand. On commercial farms, stud breeders (5/17) used an extra brand on stud cattle, while on village farms additional brands (e.g., letters, names, certain signs) as well as markings (e.g., dew-lap skin-flap cutting; see Appendix E) were used for security and easy identification. Rebranding of cattle that change ownership was also common. Branding was also used on village farms for treatment of musculoskeletal problems (e.g., hip tendon slipping), with cattle being branded over the affected site. Branding for security reasons was most common in semi-commercial areas, due to the high levels of stock theft in such areas. Furthermore, on village farms, ear notching (with knives), was used in addition to compulsory ear tagging because of the perception that ear tags were easily lost or dislodged. Thus, cattle identification, for whatever reason, was a welfare issue on all farms, especially village farms. On the other hand, the national traceability system (NamLITS) benefits cattle movement control [36], which is itself a critical underpinning of the Namibian beef industry. There would be great value in reducing the need to use painful methods for such identification.

There were differences between systems in measures related to stock handling. Only $6 \%$ of commercial herds had poor cattle flow/handling, compared to $50 \%$ and $70 \%$ in communal and semi-commercial herds, respectively. The effects of farm type on cattle handling were determined by differences in yard design and quality. For commercial 
farms with marginal flow, the main issues were related to yard design (e.g., oversized holding pens, sharp corners, and poor accessibility of the forcing pen). The problems on village farms were more fundamental, notably lack of gates, races, and forcing pens. In semi-commercial village farms yards were well constructed (usually) with wooden poles, whereas some communal villages yards were partially, or fully, constructed using thorny bushes. Thus, on village farms, poor construction and poor design of yards resulted in poor cow flow and subsequently increased handling times, frequency of hitting and tail twisting, and noise of handlers.

Despite differences across farm types in facilities and stock handling behavior, there was no farm type effect on behavior related to handling (fearful/agitated, fall/lie, stumble and run). This may be related to the "flighty" temperament of the Brahman breed which was predominant across all farm types [37]. For example, Brahman cattle and their crosses lay down in the race more commonly than other breeds, contributing to the high proportion of fall/lie cows in this study across all farm types.

Importantly, however, not all issues related to cow handling were worse on village farms. Electric prodders were only present on commercial farms (5/17); and all these farmers were using prodders on more than the $1 \%$ recommended by Grandin [38]. The use of prodders was related to cow flow in the yards with marginal designs and cattle lying in the race. The data from this study on stock handling suggest that improvements are needed across all farm types. In particular, training on alternatives to sticks, whips, pipes, and prods, such as flags on sticks $[39,40]$ is needed. It also reinforced the value of a race in reducing stress during handling [41,42], especially for extensively reared cattle that are not frequently restrained [43].

\section{Conclusions}

The study evaluated the welfare of beef cattle in the various extensive beef production systems of Namibia. It showed that the welfare of cows varied between farm types: 25 of the 44 criteria in the present study varied across systems. Of those 25 measures, the welfare outcome was better on commercial herds than semi-commercial herds in 16 and better than communal in 19. The main reason for the better performance of commercial herds were better nutrition and management of grazing land, better cattle handling infrastructure, and preventative disease control. Despite the similar animal welfare challenges facing semi-commercial and their communal counterparts, of the 25 measures found to be affected by farm type, 9 were better on semi-commercial herds than communal herds and only 2 were better on communal than semi-commercial herds. This suggests that even limited commercialization of communal farming may have benefits for animal welfare. However, this conclusion needs testing on more farms in more areas of Namibia. There is an immediate need however, to categorize measures across the farm production systems to indicate thresholds of acceptable and unacceptable welfare, to give guidance regarding the levels at which intervention and remediation is required. This will be addressed in a companion Part 2 paper of the current study.

Author Contributions: Conceptualization, Y.B.K., R.L., R.H. and K.S.; methodology, Y.B.K.; validation, K.S.; formal analysis, Y.B.K. and R.L.; investigation, Y.B.K.; writing-original draft preparation, Y.B.K.; writing-review and editing, Y.B.K., R.L., R.H., K.S. and T.P.; supervision, R.L.; funding acquisition, R.L. All authors have read and agreed to the published version of the manuscript.

Funding: This research received no external funding but funded from Massey University IVABS.

Institutional Review Board Statement: The study did not require ethical approval. It was an observational study during pregnancy testing of cows. Cows were not handled or yarded for a longer duration because of the study, had no additional induced activity/yarding/handling or manipulation.

Acknowledgments: The authors gratefully acknowledge farmers for participating in this study. The University of Namibia: School of Veterinary Medicine for logistics and Multi-Disciplinary Research Center (Davis Mumbengegwi) for vehicle provision. Baby acknowledges with sincere gratitude her husband Asser Katunahange, brother Mervin Tjitemisa, brother in-law Uakurama Katunahange, 
son Muza Katunange and daughter Uazuu Navara Karumendu for technical support and driving long distances to the study sites. Sincere gratitude also goes to the State Veterinary offices in Opuwo (especially Vezemba Rukoro), Okakarara and Gobabis (Ripuree Nandova) for assistance in organizing some farms/herds.

Conflicts of Interest: The authors declare no conflict of interest. The funders had no role in the design of the study; in the collection, analyses, or interpretation of data; in the writing of the manuscript, or in the decision to publish the results.

Appendix A. Table of Description of Welfare Measures Included in the Assessment Protocol for Cow-Calf Welfare in Namibia (Kaurivi et al., 2020c)

$\begin{array}{ccc}\text { Welfare } & \text { Welfare Criteria } & \text { Assessment Method } \\ \text { Principle } & \text { Welfare Measures } & \text { Observations Made In The Race Or } \\ \text { In Holding Pens If No Race }\end{array}$

$\%$ thin cows in the herd based on score 1-2.5 on the 5-point BCS scale that is commonly used in

Body condition score (BCS)

Namibia. Due to the drought conditions, another score of severity was added to differentiate between thin ( $>2-2.5$ scale) and very thin/emaciated (1-2 scale) cows.

Absence of hunger

Rumen fill score (RFS)

$\%$ of cows with hollow/empty rumen.

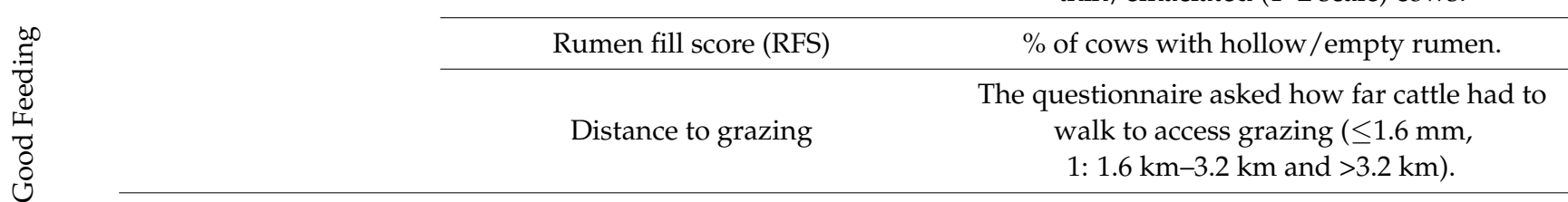

Average distance to water source. Distance to water in semi-commercial and communal

Absence of thirst Distance to water villages was estimated as the distance to grazing as water points are close to yards and cattle come to drink after grazing $(\leq 1.6 \mathrm{~mm}$, 1: $1.6 \mathrm{~km}-3.2 \mathrm{~km}$ and $>3.2 \mathrm{~km})$.

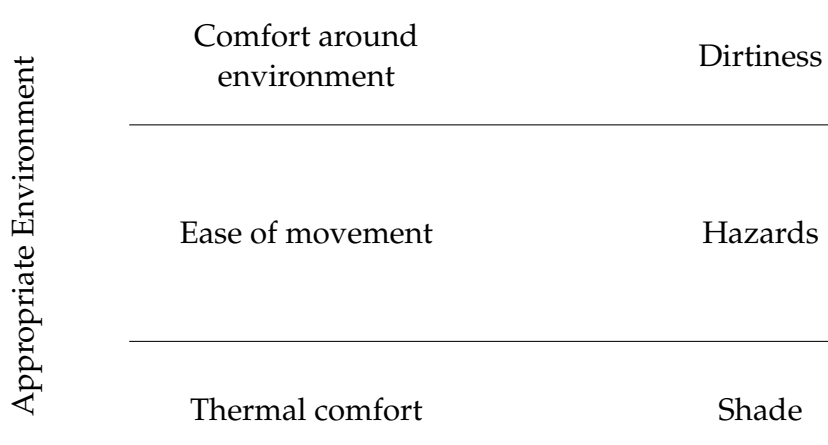

"Dirtiness" recorded by averaging the three measures of dirty tails, dirty hind quarters, and dirty flanks.

Identify pasture hazards (e.g., steep hills) and presence of dangerous objects/garbage, and loss of animals to such hazards: (1) no hazards, (2) 1 or 2 hazards and (3) 3 or more hazards or animals dying in any hazard.

Subjective assessment of shade in the paddocks (presence of trees, shrubs, galleys, synthetic canopies) as enough or insufficient.

Abrasions, Swelling, and Hair loss

$\%$ of cows with abrasions/fresh scratches or cuts, swellings and hairless patches extending $>1 \mathrm{~cm}$.

\begin{tabular}{|c|c|c|}
\hline \multirow{3}{*}{$\begin{array}{l}\text { Absence of } \\
\text { injuries/physical } \\
\text { impairment }\end{array}$} & $\begin{array}{l}\text { Extraneous (multiple) } \\
\text { brands/wounds/cuts }\end{array}$ & $\begin{array}{l}\text { Observation of brand mark wounds }(>2 \mathrm{~cm} \text { ) or } \\
\text { more than once branded } / \text { marked (i.e., stock } \\
\text { brand, initials or name of a farmer branded) and } \\
\text { extraneous cuts (i.e., dew-lap skin cuts). }\end{array}$ \\
\hline & Long/sharp horns & $\begin{array}{l}\text { Number of observed cows with sharp/long } \\
\text { horns ( }>5 \mathrm{~cm} \text { in length, sharp and forward facing } \\
\text { to pose a risk of injuring others). }\end{array}$ \\
\hline & Broken tails & $\begin{array}{l}\text { Observations of abnormal tails (misaligned or } \\
\text { broken at the tail head). }\end{array}$ \\
\hline
\end{tabular}




\begin{tabular}{|c|c|c|c|}
\hline $\begin{array}{l}\text { Welfare } \\
\text { Principle }\end{array}$ & Welfare Criteria & Welfare Measures & $\begin{array}{l}\text { Assessment Method } \\
\text { Observations Made In The Race Or } \\
\text { In Holding Pens If No Race }\end{array}$ \\
\hline & \multirow{7}{*}{$\begin{array}{l}\text { Absence of disease } \\
\text { and pain }\end{array}$} & Blindness & $\begin{array}{l}\% \text { of cows with affected eye(s) by visual } \\
\text { assessment and/or testing with hand. }\end{array}$ \\
\hline & & Ocular discharges & $\begin{array}{c}\% \text { of cows with ocular } \\
\text { discharges extending } 2 \mathrm{~cm} \text {. }\end{array}$ \\
\hline & & Nasal discharges & $\%$ of cows with nasal discharges extending $2 \mathrm{~cm}$. \\
\hline & & Lameness & $\begin{array}{c}\% \text { of cows with unsteady gait exciting the race to } \\
\text { paddocks or from the holding pen } \\
\text { to the paddocks. }\end{array}$ \\
\hline & & Diarrhea & $\%$ of cows with diarrhea. \\
\hline & & Dystocia & $\begin{array}{l}\% \text { reported by famers during } \\
\text { questionnaire-guided interview. }\end{array}$ \\
\hline & & Mortality & $\begin{array}{l}\% \text { of cattle which had accidental deaths and } \\
\text { deaths / slaughter on-farm due to disease were } \\
\text { combined. It was emphasized that mortality rate } \\
\text { included deaths due to predators, toxic plants, } \\
\text { and snake bites. }\end{array}$ \\
\hline & External parasites & $\begin{array}{l}\text { Fly burden } \\
\text { Tick burden }\end{array}$ & $\begin{array}{l}\text { Separate impression of more than } 20 \text { number of } \\
\text { flies (i.e., horse flies) and } \\
\text { ticks on any part of the body of a cow. }\end{array}$ \\
\hline & $\begin{array}{l}\text { Painful management } \\
\text { procedures }\end{array}$ & $\begin{array}{c}\text { Castration, } \\
\text { Disbudding, } \\
\text { Ear tagging/notch }\end{array}$ & $\begin{array}{l}\text { Record age and use of local anesthetic on a } \\
\text { 3-point level: (1) No disbud/castration, } \\
\text { ( } 2) \leq 2 \text { months and ( } 3)>2 \text { months. } \\
\text { For ear tagging/notching the scoring was: no tag } \\
\text { or use anesthetics; tag with no anesthetics and } \\
\text { notching/cutting with no anesthetics. }\end{array}$ \\
\hline & & Hot-iron branding & $\begin{array}{l}\text { Record age of branding and use of local } \\
\text { anesthetic (in questionnaire) on a 3-point score: } \\
\text { (1) no branding or use anesthetics, (2) one brand } \\
\text { (compulsory) and (3) more than } 1 \text { brand. }\end{array}$ \\
\hline \multirow{4}{*}{ 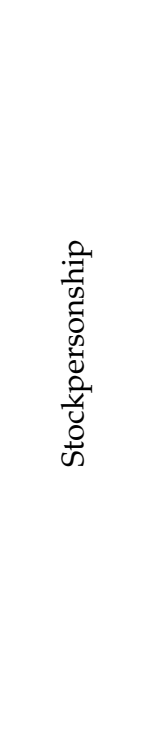 } & \multirow{4}{*}{$\begin{array}{l}\text { Animal handling } \\
\text { stock-personship and } \\
\text { resource-based } \\
\text { measures }\end{array}$} & Fearful/agitated & $\begin{array}{l}\% \text { cows fearful/agitated in the race/forcing pen } \\
\text { (climbing on others). }\end{array}$ \\
\hline & & Running & $\begin{array}{l}\% \text { of cows running (taking } \geq 2 \text { strides at a gait } \\
\text { faster than a trot) when cows exit from the race } \\
\text { or holding pen to the paddocks. }\end{array}$ \\
\hline & & Stumbling & $\begin{array}{l}\text { \% of cows stumbling were cows with their } \\
\text { knees/hocks contacted the ground, on exiting } \\
\text { the race or if moving into a group of cows } \\
\text { include assessment from holding pen to the } \\
\text { paddocks. Also included those cattle stumbling } \\
\text { in the holding pens when being drafted for } \\
\text { restraint in the absence of a race. }\end{array}$ \\
\hline & & Falling & $\begin{array}{l}\% \text { of cows falling (torso contacted the ground) or } \\
\text { lying down while in the race and forcing pen } \\
\text { were recorded. Also include those cattle falling } \\
\text { in the holding pens when being drafted for } \\
\text { restraint in the absence of a race. }\end{array}$ \\
\hline
\end{tabular}




$\begin{array}{ccc}\begin{array}{c}\text { Welfare } \\ \text { Principle }\end{array} & \text { Welfare Criteria } & \text { Assessment Method } \\ & \text { Welfare Measures } & \begin{array}{c}\text { Observations Made In The Race Or } \\ \text { In Holding Pens If No Race }\end{array}\end{array}$

Subjective categorical observation of the group rather than the individual cow: (1) no hitting; (2) occasional hitting ( $\leq 10 \%$ of cows); (3) frequent

Hitting cows hitting ( $>10 \%$ of cows) into the forcing pen and race. Included proportion of cattle hit in pens when being drafted for restraining in the absence of a race.

Estimate the proportion of cows that were prodded with an electrical goad on any part of

Use of electrical prodders the body while drafted or standing in the race, pens or yards on a 3-point level: (1) no prodding,

(2) few/occasional prod ( $\leq 1 \%$ cows) and (3) many/frequent prod ( $>1 \%$ cows prodded).

Estimate the proportion of cows with tail twisted while drafted or standing in the race or pens on a

Tail twisting 3-point level: (1) no twisting, (2) occasional/few twist ( $\leq 10 \%$ of cows) and (3) frequent twist ( $>10 \%$ of cows).

Estimate of the proportion of cows that were mis-caught on any part of the body while gates were closed into or within the race. If no race, available mis-catch was recorded if more than

Mis-catching one attempt was made to capture/restrain an individual animal with ropes or if a cow did not stand still when a rope was secured around the legs.

\begin{tabular}{|c|c|}
\hline $\begin{array}{l}\text { Noise of Handlers } \\
\text { Noise of Equipment/ } \\
\text { machinery }\end{array}$ & $\begin{array}{l}\text { Subjective categorical assessment of handlers' } \\
\text { noise (e.g., shouting) and equipment noise } \\
\text { (e.g., race or chute gate) and machinery } \\
\text { (e.g., generators etc.): (1) no noise, (2) minor less } \\
\text { frequent audible noise or (3) repeated, } \\
\text { unpleasantly noisy. }\end{array}$ \\
\hline Dogs noise around the yard & $\begin{array}{l}\text { Categorical subjective assessment: (1) no dogs; } \\
\text { (2) quiet dogs; (3) Noisy or } \\
\text { repeatedly audible dogs. }\end{array}$ \\
\hline Health checks & $\begin{array}{l}\text { Record frequency of health checks on cows } \\
\text { during winter/pregnancy: (1) daily, } \\
\text { (2) once-twice/week and (3) more than weekly. }\end{array}$ \\
\hline Yarding frequency & $\begin{array}{l}\text { Record frequency (number of times) of yardings } \\
\text { per year. Emphasized cattle yardings that only } \\
\text { involve restraining (e.g., vaccinations and } \\
\text { tagging); (1) }>4 \text { times, (2) } 3-4 \text { times and } \\
\text { (3) } 0-2 \text { times. }\end{array}$ \\
\hline Yard design flow & $\begin{array}{l}\text { In the absence of a race, assessment included } \\
\text { farmers' cattle handling skills and movement: (1) } \\
\text { effective handling (manual restraint of cows was } \\
\text { easily achieved), (2) minor issues with flow } \\
\text { and/or restraint/of cattle, (3) major issues with } \\
\text { flow and/or restraint (e.g., lengthy periods of } \\
\text { running behind cows while trying to capture and } \\
\text { restrain them). }\end{array}$ \\
\hline
\end{tabular}




\section{Appendix B. Questionnaire-Guided Interview Questions Used for Welfare Assessment at Beef Herds in the Production Systems in Namibia}

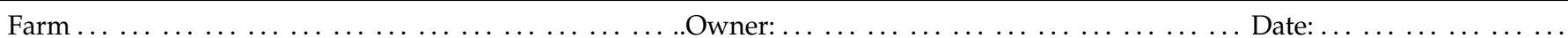

Questionnaire-guided interview questions (based on UC Davis cow and calf animal welfare assessment protocol, 2016) will address the following welfare management related questions on each farm.

a. Please state your cattle herd number ( ), number of breeding females ( ) and number of males/bulls ( )

b. Which type and numbers of other animals you have on the farm (breed, class)?

\section{General Herd Management}

1. How are your cattle identified (ear tag, ear notch, branded, other marking)? At what age?

2. Do you do dehorn or disbudding operations on your cattle? At what age? Which method?

3. Do you castrate your cattle? At what age? Which method?

4. At what age are your calves weaned? How?

5. What is the source of water for cattle on the farm? How far do cattle walk to water source?

6. Do you monitor the grazing of your cattle? How often? How far do cattle walk to grazing?

7. What is the condition of grazing (quantity and quality)? Stocking density rate/carrying capacity?

8. What are the main supplementary feeds for cattle used? Any other wintering practices that you do regarding feeding of animals? What is the general body condition of cattle now?

9. Do you get veterinarian or veterinary services visits? How often? What purpose?

10. What training do you have relating to animal health and husbandry? How do you keep abreast?

\section{Stockpersonship}

11. How many handlers per stock do you have on the farm (ratio of staff per stock unit)?

12. How frequently do you yard cattle for handling/restraining? For what purpose?

13. Do you use any other handling devices (sticks, ropes, plastics) to handle the cattle?

14. Do you use horses to handle the cattle on the farm? Do you use dogs in the cattle yards?

\section{Health}

15. Do you do health checks on your cattle (especially pregnant cows)? How often or when?

16. In the last year, how many cattle did you cull for any health-related issues?

17. How many died from diseases/disorders/deficiency? What were the main causes of sickness and deaths of cattle on the farm? (Respiratory, diarrhea, bloat, pink eyes, lameness, lumpy skin disease, botulism? udder problems etc.)

18. What were the main clinical signs of unknown causes of cattle sickness and deaths on the farm? Any other disease or health abnormalities in the herd?

19. What treatments are you likely to perform on your cattle? How many cattle recovered from treatment?

20. Do you vaccinate your cattle? For which diseases? When or how often?

21. Do you control internal and external parasite on your cattle? How/With what products? When or how often?

22. Do you get animals injured in the yard, chute/race or paddocks? How many? From what exactly?

23. Have you lost animals from hazards (falling in dams/creeks, hills etc., wire sticking etc.)? How many and from what exactly?

24. Do you get cattle injured in the yard (kraal), paddocks (camps) or chute (manga? How many?

25. Do you lose animals from poisonous plant/other poisoning? Which type? How many cattle died?

26. Do you have predation problems? What predators? How many cattle succumbed to the specific predators?

27. Any cattle bitten by snake? What was the outcome?

\section{Reproduction}

28. Did you experience any reproductive conditions in cattle in the last year? Which one? (Retained placenta, prolapse vagina/uterus, abortion, dystocia). How many cases of each? What was the outcome (assisted/culled/died, etc.?)

Appendix C. Table of Mean Ranks of Commercial, Semi-Commercial, and Communal Beef Cattle Production Systems in Namibia

\begin{tabular}{ccccc}
\hline Mean Ranks & $\begin{array}{c}\text { Commercial } \\
(\boldsymbol{n}=\mathbf{1 7})\end{array}$ & $\begin{array}{c}\text { Semi-commercial } \\
(\boldsymbol{n}=\mathbf{2 0})\end{array}$ & $\begin{array}{c}\text { Communal } \\
(\boldsymbol{n}=\mathbf{1 8})\end{array}$ & Mean Rank $\boldsymbol{p}$-Value \\
\hline Thin cows & 13.9 & 69.4 & 69.9 & $<0.001$ \\
Emaciated cows & 11.5 & 25.4 & 46.5 & $<0.001$ \\
Poor rumen fill & 9.6 & 29.7 & 43.5 & $<0.001$ \\
\hline
\end{tabular}




\begin{tabular}{|c|c|c|c|c|}
\hline Mean Ranks & $\begin{array}{l}\text { Commercial } \\
\quad(n=17)\end{array}$ & $\begin{array}{l}\text { Semi-commercial } \\
\quad(n=20)\end{array}$ & $\begin{array}{l}\text { Communal } \\
\qquad(n=18)\end{array}$ & Mean Rank $p$-Value \\
\hline Dirtiness & 28.2 & 23.5 & 32.8 & 0.021 \\
\hline Swelling & 25.9 & 30.3 & 27.5 & 0.470 \\
\hline Hair loss & 17.0 & 30.2 & 35.9 & 0.002 \\
\hline Abrasion & 16.3 & 25.8 & 41.4 & $<0.001$ \\
\hline Extraneous brands/cuts & 20.6 & 29.9 & 32.9 & 0.007 \\
\hline Broken tails & - & - & - & - \\
\hline Long horns & 10.1 & 32.3 & 40.2 & $<0.001$ \\
\hline Blindness & 30.9 & 26.0 & 27.5 & 0.113 \\
\hline Ocular discharge & 28.6 & 27.0 & 28.5 & 0.552 \\
\hline Nasal discharge & 28.6 & 27.0 & 28.5 & 0.552 \\
\hline Diarrhea & 31.5 & 17.5 & 36.4 & $<0.001$ \\
\hline Lameness & 24.2 & 21.4 & 39.0 & 0.001 \\
\hline Dystocia & 26.8 & 26.5 & 30.9 & 0.637 \\
\hline Tick burden & 18.5 & 31.0 & 33.6 & 0.002 \\
\hline Fly burden & 21.1 & 31.1 & 31.1 & 0.073 \\
\hline Deaths from disease & 30.0 & 24.8 & 29.7 & 0.546 \\
\hline Accidental deaths & 28.8 & 25.2 & 30.4 & 0.197 \\
\hline Culling for health & 30.3 & 25.5 & 28.7 & 0.363 \\
\hline Predation/snake & 24.4 & 17.4 & 43.1 & $<0.001$ \\
\hline a Nutritional deficiency deaths & 17.5 & 38.3 & 26.4 & 0.002 \\
\hline Poisoning deaths & 26.5 & 29.3 & 28.0 & 0.410 \\
\hline $\mathrm{b}$ Reproduction deaths & 30.4 & 23.6 & 30.6 & 0.018 \\
\hline Annual mortality rate & 13.3 & 34.0 & 35.2 & $<0.001$ \\
\hline Fearful/Agitate & 25.3 & 28.3 & 30.3 & 0.693 \\
\hline Fall/lie & 31.0 & 25.3 & 28.2 & 0.347 \\
\hline Stumble & 32.4 & 27.6 & 24.3 & 0.147 \\
\hline Run exit & 34.8 & 24.2 & 25.9 & 0.197 \\
\hline
\end{tabular}

a Nutritional deaths included weight loss and mineral deficiency (e.g., phosphate) deaths. ${ }^{\mathrm{b}}$ Reproduction related deaths included dystocia, retained placenta, and vaginal prolapse complications.

Appendix D. Table of Frequency (\%) of Categorical Measures in the 3 Welfare Scores at the Cow-Calf Production Systems Herds in Namibia (CF-Commercial $(n=17)$, SCV-Semi-Commercial $(n=20), C V-C o m m u n a l ~(n=18)$

\begin{tabular}{|c|c|c|c|c|}
\hline & $\begin{array}{c}\text { Production } \\
\text { Systems }\end{array}$ & $\begin{array}{c}\text { Good } \\
\text { Welfare }\end{array}$ & $\begin{array}{c}\text { Marginal } \\
\text { Welfare }\end{array}$ & $\begin{array}{c}\text { Poor } \\
\text { Welfare }\end{array}$ \\
\hline \multirow{3}{*}{ Water distance } & $\mathrm{CF}$ & 94 & 6 & 0 \\
\hline & SCV & 0 & 5 & 95 \\
\hline & $\mathrm{CV}$ & 0 & 0 & 100 \\
\hline \multirow{3}{*}{ Grazing distance } & $\mathrm{CF}$ & 6 & 77 & 18 \\
\hline & SCV & 0 & 5 & 95 \\
\hline & $\mathrm{CV}$ & 0 & 0 & 100 \\
\hline \multirow{3}{*}{ Hazards } & $\mathrm{CF}$ & 0 & 88 & 12 \\
\hline & SCV & 0 & 65 & 35 \\
\hline & $\mathrm{CV}$ & 0 & 67 & 33 \\
\hline \multirow{3}{*}{ Dehorning } & $\mathrm{CF}$ & 47 & 53 & 0 \\
\hline & SCV & 20 & 5 & 75 \\
\hline & $\mathrm{CV}$ & 33 & 0 & 67 \\
\hline \multirow{3}{*}{ Castration } & $\mathrm{CF}$ & 47 & 18 & 35 \\
\hline & SCV & 15 & 0 & 85 \\
\hline & $\mathrm{CV}$ & 33 & 0 & 67 \\
\hline
\end{tabular}




\begin{tabular}{|c|c|c|c|c|}
\hline & $\begin{array}{l}\text { Production } \\
\text { Systems }\end{array}$ & Good Welfare & $\begin{array}{c}\text { Marginal } \\
\text { Welfare }\end{array}$ & Poor Welfare \\
\hline \multirow{3}{*}{ Ear tagging } & $\mathrm{CF}$ & 0 & 100 & 0 \\
\hline & SCV & 0 & 5 & 95 \\
\hline & $\mathrm{CV}$ & 0 & 0 & 100 \\
\hline \multirow{3}{*}{$\begin{array}{l}\text { Hot-iron } \\
\text { branding }\end{array}$} & $\mathrm{CF}$ & 0 & 82 & 18 \\
\hline & SCV & 0 & 5 & 95 \\
\hline & $\mathrm{CV}$ & 0 & 83 & 17 \\
\hline \multirow{3}{*}{ Mis-catch } & $\mathrm{CF}$ & 71 & 24 & 6 \\
\hline & SCV & 95 & 5 & 0 \\
\hline & $\mathrm{CV}$ & 100 & 0 & 0 \\
\hline \multirow{3}{*}{$\begin{array}{l}\text { Electrical } \\
\text { prodders }\end{array}$} & $\mathrm{CF}$ & 71 & 0 & 29 \\
\hline & SCV & 100 & 0 & 0 \\
\hline & $\mathrm{CV}$ & 100 & 0 & 0 \\
\hline \multirow{3}{*}{ Hitting } & $\mathrm{CF}$ & 35 & 35 & 29 \\
\hline & SCV & 35 & 30 & 35 \\
\hline & $\mathrm{CV}$ & 22 & 39 & 39 \\
\hline \multirow{3}{*}{ Tail twisting } & $\mathrm{CF}$ & 0 & 88 & 12 \\
\hline & SCV & 15 & 65 & 20 \\
\hline & $\mathrm{CV}$ & 28 & 39 & 33 \\
\hline \multirow{3}{*}{ Handlers noise } & $\mathrm{CF}$ & 12 & 82 & 6 \\
\hline & SCV & 30 & 45 & 25 \\
\hline & $\mathrm{CV}$ & 0 & 50 & 50 \\
\hline \multirow{3}{*}{ Equipment noise } & $\mathrm{CF}$ & 53 & 35 & 12 \\
\hline & SCV & 85 & 10 & 5 \\
\hline & $\mathrm{CV}$ & 83 & 17 & 0 \\
\hline \multirow{3}{*}{ Dogs noise } & $\mathrm{CF}$ & 71 & 24 & 6 \\
\hline & SCV & 90 & 10 & 0 \\
\hline & $\mathrm{CV}$ & 100 & 0 & 0 \\
\hline \multirow{3}{*}{ Health checks } & $\mathrm{CF}$ & 94 & 6 & 0 \\
\hline & SCV & 100 & 0 & 0 \\
\hline & $\mathrm{CV}$ & 100 & 0 & 0 \\
\hline \multirow{3}{*}{$\begin{array}{l}\text { Yarding/handling } \\
\text { frequency }\end{array}$} & $\mathrm{CF}$ & 24 & 71 & 6 \\
\hline & SCV & 20 & 55 & 25 \\
\hline & $\mathrm{CV}$ & 0 & 11 & 89 \\
\hline \multirow{3}{*}{$\begin{array}{c}\text { Yard } \\
\text { flow/handling }\end{array}$} & $\mathrm{CF}$ & 53 & 41 & 6 \\
\hline & SCV & 5 & 25 & 70 \\
\hline & $\mathrm{CV}$ & 0 & 50 & 50 \\
\hline
\end{tabular}

Highest frequency for each poor welfare category is in bold. 
Appendix E. Pictures of Various Identification Markings at the Beef Cattle Herds in Namibia. Top Pictures Show the Skin-Flap Cuttings and Bottom Right Cow Has a Sign for Easy Identification and Bottom Left Shows a Cow with Multiple Brands for Traditional Treatment
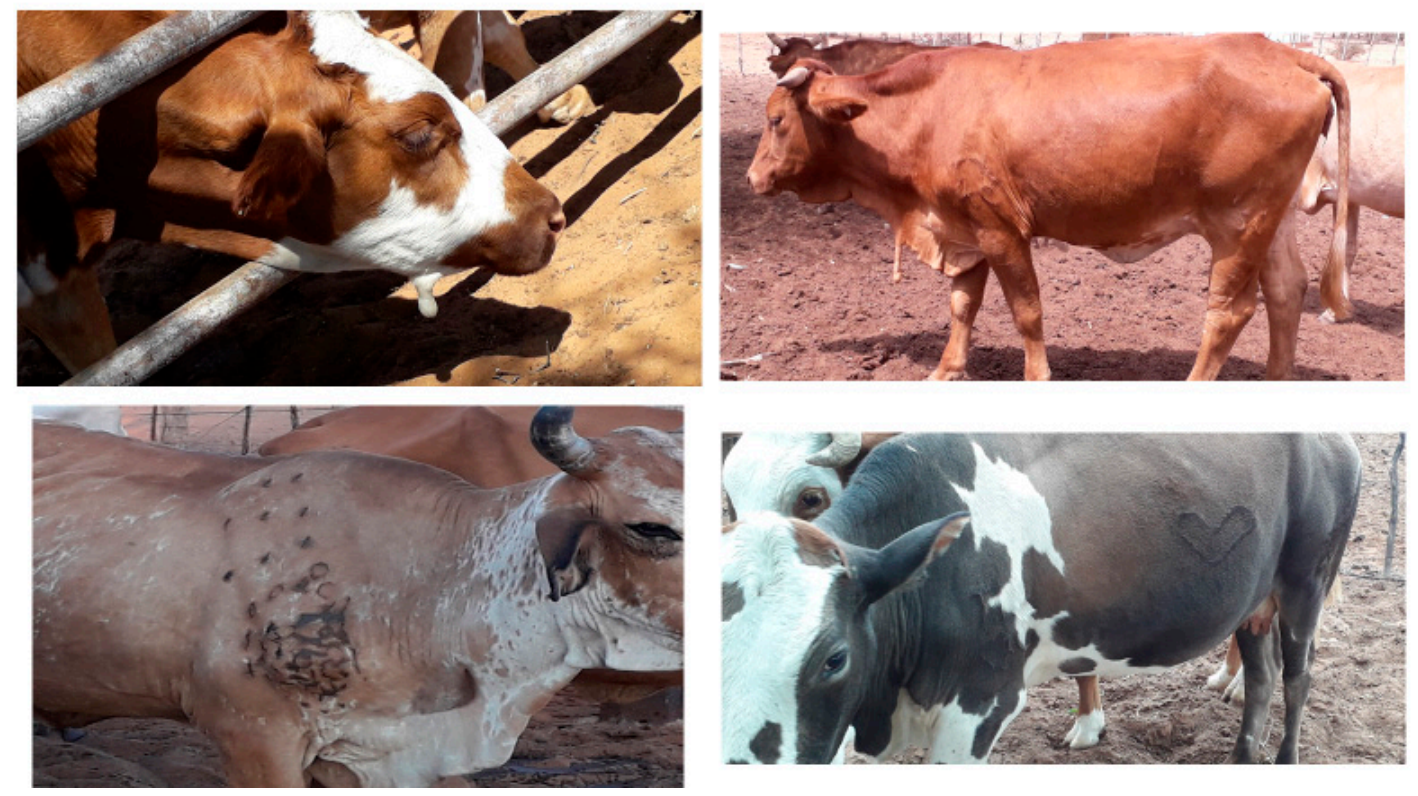

\section{References}

1. Rothauge, A.; Smit, G.N.; Abate, A.L. The diet selected by free-ranging beef cattle and its effect on the condition of a semi-arid savanna in Namibia. In Agricola; Ministry of Agriculture, Water and Forestry, Ed.; Ministry of Agriculture, Water and Forestry: Windhoek, Namibia, 2007; Volume 1.

2. Olbrich, R.; Quaas, M.F.; Baumgartner, S. Characterizing commercial cattle farms in Namibia: Risk, management, and sustainability. Afr. J. Agric. Res. 2016, 11, 4109-4120. [CrossRef]

3. Naziri, D.; Rich, K.M.; Bennett, B. Would a commodity-based trade approach improve market access for Africa? A case study of the potential of beef exports from communal areas of Namibia. Dev. Pol. Rev. 2015, 33, 195-219. [CrossRef]

4. MAWF. Ministry of Agriculture, Water and Forestry Annual Report 2016/2017; Ministry of Agriculture, Water and Forestry (MAWF): Windhoek, Namibia, 2017; pp. 23-30.

5. Mendelsohn, J. Farming Systems in Namibia; Research \& Information Services of Namibia (RAISON): Windhoek, Namibia, 2006.

6. Mendelsohn, J.M. Customary and Legislative Aspects of Land Registration and Management on Communal Land in Namibia; Research \& Information Services of Namibia (RAISON): Windhoek, Namibia, 2008.

7. Siegmund-Schultze, M.; Lange, F.; Schneiderat, U.; Steinbach, J. Performance, management and objectives of cattle farming on communal ranges in Namibia. J. Arid. Environ. 2012, 80, 65-73. [CrossRef]

8. Winckler, C. Assessment of cattle welfare: Approaches, goals, and next steps on farms. In Advances in Cattle Welfare; Tucker, C.B., Ed.; Woodhead Publishing: Cambridge, UK, 2018; pp. 55-69. [CrossRef]

9. Kaurivi, Y.B.; Laven, R.; Hickson, R.; Parkinson, T.; Stafford, K. Developing an Animal Welfare Assessment Protocol for Cows in Extensive Beef Cow-Calf Systems in New Zealand. Part 1: Assessing the Feasibility of Identified Animal Welfare Assessment Measures. Animals 2020, 10, 1597. [CrossRef]

10. Dunston-Clarke, E.; Willis, R.S.; Fleming, P.A.; Barnes, A.L.; Miller, D.W.; Collins, T. Developing an Animal Welfare Assessment Protocol for Livestock Transported by Sea. Animals. 2020, 10, 705. [CrossRef]

11. Laven, R.A.; Fabian, J. Applying animal-based welfare assessments on New Zealand dairy farms: Feasibility and a comparison with United Kingdom data. N. Z. Vet. J. 2016, 64, 212-217. [CrossRef]

12. Hernández, A.; König, S.E.; Zúñiga, J.J.R.; Galina, C.S.; Berg, C.; Gonzales, M.R.; Villalobos, A.D. Implementation of the welfare Quality ${ }^{\circledR}$ protocol in dairy farms raised on extensive, semi-intensive and intensive systems in Costa Rica. J. Anim. Behav. Biomet. 2017, 5, 132-138. [CrossRef]

13. Kaurivi, Y.B.; Laven, R.; Hickson, R.; Stafford, K.; Parkinson, T. Assessing Extensive Beef Cow-Calf Welfare in Namibia: Feasibility of adapting a New Zealand animal welfare assessment protocol. J. Appl. Anim. Welf. Sci. 2020. under review.

14. Welfare Quality. Welfare Quality Assessment Protocol for Cattle. In Welfare Quality Assessment Protocol for Cattle (without Veal Calves); Welfare Quality®: Lelystad, The Netherlands, 2009; pp. 1-142.

15. UC Davis University of California. Davis Cow-Calf Health and Handling Assessment. Available online: https://www. ucdcowcalfassessment.com/ (accessed on 12 August 2017). 
16. Engler, J.-O.; von Wehrden, H.; Baumgärtner, S. Determinants of farm size and stocking rate in Namibian commercial cattle farming. Land Use Policy 2019, 81, 232-246. [CrossRef]

17. Grant, C.; Biggs, H.; Meissner, H. Demarcation of potentially mineral-deficient areas in central and northern Namibia by means of natural classification systems. Onderstepoort J. Vet. Res. 1996, 63, 109-120.

18. Climate-Data. Namibia Climate. Available online: https:/ / en.climate-data.org/africa/namibia-89 (accessed on 8 October 2020).

19. WSPA. Animal Welfare: Adding Value to the Livestock and Meat Trade. Namibia: Case Study; WSPA: Windhoek, Namibia, 2013. Available online: http://worldanimal.net/images/stories/documents/Case_Studies/Namibia-meat-case-study.pdf (accessed on 16 April 2020).

20. Inman, E.N.; Hobbs, R.J.; Tsvuura, Z.; Valentine, L. Current vegetation structure and composition of woody species in communityderived categories of land degradation in a semiarid rangeland in Kunene region, Namibia. Land Degrad. Dev. 2020, 31, 2996-3013. [CrossRef]

21. CBRLM. Community-Based Rangeland and Livestock Management: NAMIBIA; MCA Namibia, Ed.; Millenium Challenge Corporation: Windhoek, Namibia, 2014. Available online: http:/ / www.the-eis.com/data/literature/Community20based20rangeland2 Omanagement20CBRLM20Final20Report.pdf (accessed on 15 May 2020).

22. Hart, R.H.; Bissio, J.; Samuel, M.J.; Waggoner, J.W., Jr. Grazing systems, pasture size, and cattle grazing behavior, distribution and gains. J. Range Manag. 1993, 46, 81-87. [CrossRef]

23. Chesterton, R.; Pfeiffer, D.; Morris, R.; Tanner, C. Environmental and behavioural factors affecting the prevalence of foot lameness in New Zealand dairy herds-A case-control study. N. Z. Vet. J. 1989, 37, 135-142. [CrossRef] [PubMed]

24. Hund, A.; Chiozza Logroño, J.; Ollhoff, R.D.; Kofler, J. Aspects of lameness in pasture based dairy systems. Vet. J. 2019, 244, 83-90. [CrossRef]

25. Sadiq, M.B.; Ramanoon, S.Z.; Mossadeq, W.M.S.; Mansor, R.; Syed-Hussain, S.S. Association between lameness and indicators of dairy cow welfare based on locomotion scoring, body and hock condition, leg hygiene and lying behavior. Animals 2017, 7, 79. [CrossRef]

26. Dickman, A.; Rust, N.A.; Boast, L.K.; Wykstra, M.; Richmond-Coggan, L.; Klein, R.; Selebatso, M.; Msuha, M.; Marker, L. The Costs and Causes of Human-Cheetah Conflict on Livestock and Game Farms. In Cheetahs: Biology and Conservation; Nyhus, P.J., Marker, L., Boast, L.K., Schmidt-Küntzel, A., Eds.; Academic Press: Cambridge, MA, USA, 2018; pp. 173-189. [CrossRef]

27. Allen, L.R. Wild dog control impacts on calf wastage in extensive beef cattle enterprises. Anim. Prod. Sci. 2014, 54, 214-220. [CrossRef]

28. Du Plessis, J.; Avenant, N.; Botha, A.; Mkhize, N.; Müller, L.; Mzileni, N.; O’Riain, M.J.; Parker, D.M.; Potgieter, G.; Richardson, P.R.K.; et al. Past and current management of predation on livestock. Livestock Predation and Its Management in South Africa: A Scientific Assessment; Centre for African Conservation Ecology, Nelson Mandela University: Port Elizabeth, South Africa, 2018 ; pp. 125-177.

29. Burns, B.M.; Fordyce, G.; Holroyd, R.G. A review of factors that impact on the capacity of beef cattle females to conceive, maintain a pregnancy and wean a calf-Implications for reproductive efficiency in northern Australia. Anim. Reprod. Sci. 2010, 122, 1-22. [CrossRef]

30. Suttle, N. Mineral Nutrition of Livestock; CABI: Wallingford, UK, 2010; p. 122-167-p. [CrossRef]

31. FAN Meat. Farmers Pocket Guide to the Namibian Meat Scheme. In Farm Assured Namibian Meat Scheme; Meat Board of Namibia: Windhoek, Namibia, 2018. Available online: https:/ /www.nammic.com.na/index.php/library/summary/56-guide/176-fanmeat-pocket-guide (accessed on 15 May 2020).

32. Stafford, K.J.; Chambers, J.P.; Mellor, D.J. The alleviation of pain in cattle: A review. CAB Rev. Perspect. Agric. Vet. Sci. Nutr. Nat. Resour. 2006, 1, 7. [CrossRef]

33. Bretschneider, G. Effects of age and method of castration on performance and stress response of beef male cattle: A review. Livest. Prod. Sci. 2005, 97, 89-100. [CrossRef]

34. Stafford, K.J.; Mellor, D.J. Addressing the pain associated with disbudding and dehorning in cattle. Appl. Anim. Behav. Sci. 2011, 135, 226-231. [CrossRef]

35. Knierim, U.; Irrgang, N.; Roth, B.A. To be or not to be horned-Consequences in cattle. Livest. Sci. 2015, 179, 29-37. [CrossRef]

36. Prinsloo, T.; de Villiers, C. A framework to define the impact of sustainable ICT for agriculture projects: The Namibian livestock traceability system. Electron. J. Inf. Syst. Dev. Ctries. 2017, 82, 1-22. [CrossRef]

37. Cooke, R.F.; Arthington, J.D.; Araujo, D.B.; Lamb, G.C. Effects of acclimation to human interaction on performance, temperament, physiological responses, and pregnancy rates of Brahman-crossbred cows. J. Anim. Sci. 2009, 87, 4125-4132. [CrossRef] [PubMed]

38. Grandin, T. Livestock-handling quality assurance. J. Anim. Sci. 2001, 79, E239-E248.

39. Grandin, T. Animal welfare and society concerns finding the missing link. Meat Sci. 2014, 98, 461-469. [CrossRef]

40. Madzingira, O. Animal Welfare Considerations in Food-Producing Animals. In Animal Welfare; IntechOpen: London, UK, 2018; p. 99. [CrossRef]

41. Grandin, T. Handling facilities and restraint of extensively raised range cattle. In Livestock Handling and Transport, 4th ed.; CABI: Wallingford, Cambridge, UK, 2014; pp. 94-115.

42. Simon, G.E.; Hoar, B.R.; Tucker, C.B. Assessing cow-calf welfare. Part 1: Benchmarking beef cow health and behavior, handling; and management, facilities, and producer perspectives. J. Anim. Sci. 2016, 94, 3476-3487.

43. Petherick, J.C. Animal welfare issues associated with extensive livestock production: The northern Australian beef cattle industry. Appl. Anim. Behav. Sci. 2005, 92, 211-234. [CrossRef] 